\title{
O Movimento Feminino pela Anistia na luta contra a ditadura no Brasil: entrevista com Therezinha Zerbini
}

The Movimento Feminino pela Anistia in the Fight Against the Dictatorship in Brazil: Interview With Therezinha Zerbini

Ana Rita Fonteles Duarte

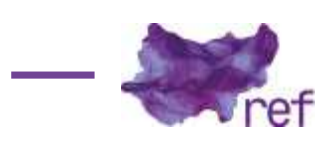

É impossível desvincular a origem e construção do Movimento Feminino pela Anistia (MFPA) de sua liderança. A advogada, falecida em 2015, aos 87 anos, foi idealizadora do Movimento, criado em 1975 em São Paulo, e participou ativamente dos momentos de implantação. Esteve presente na condução política do Movimento, na fundação dos núcleos e influenciou na escolha de dirigentes, organização de atos públicos e na redação de periódicos e documentos.

Seu papel foi reconhecido pelos órgãos de repressão, à época sendo considerada "conhecida subversiva". Casada com general resistente ao Golpe de 1964, foi presa pela Operação Bandeirantes, por intermediar o empréstimo do sítio onde foi realizado o congresso clandestino da União Nacional dos Estudantes, em Ibiúna, em 1968.

Na entrevista abaixo, concedida em 31 de agosto de 2006, em sua casa, em São Paulo, por ocasião da elaboração de minha tese de doutorado sobre o Movimento que dirigiu, a controversa senhora falou sobre as estratégias de organização do MFPA, o recrutamento de mulheres pelo Brasil e seus embates com militares, feministas e homens de esquerda na construção da luta pela anistia no Brasil.

\section{Ana Rita Fonteles Duarte (ARFD): Como se deu a organização do MFPA?}

Therezinha Zerbini (TZ): Você está vendo aí uma mesa de refeição, com oito mulheres, com muita fé, muita garra e foi tão simples o nosso manifesto que sempre é bom... Recordar é viver (pega os óculos e lê): "Manifesto da Mulher brasileira em Favor da Anistia. Nós, mulheres brasileiras, assumimos nossas responsabilidades de cidadãs no quadro político nacional. Através da história, provamos o espírito solidário da mulher, fortalecendo aspirações de amor e justiça. Eis porque nós nos antepomos (interrompe e diz: 'Eu não gostei disso, mas uma das pessoas que estava queria pôr essa palavra, era uma escritora e acabou ficando') aos destinos da nação, que só cumprirá sua finalidade de paz se for concedida anistia ampla e geral a todos aqueles que foram atingidos pelos atos de exceção. Conclamamos todas as mulheres, no sentido de se unirem a este movimento, procurando o apoio de todos quantos se identifiquem com a ideia da necessidade da anistia, tendo em vista um dos objetivos nacionais: a união da nação" (Therezinha ZERBINI, 1979, p. 27). Naquele meu tempo era ainda xérox. Eu tirei xérox, mandei para o Rio Grande do Sul. Lá estava a Dilma Roussef, que foi presa comigo. A ministra Dilma Roussef (no momento da entrevista, Dilma era ministra de Minas e Energia do Governo Lula) é uma pessoa extraordinária, inteligentíssima, culta, de real valor, uma mulher muito séria. Ela bem mais moça do que eu. Eu tinha 52 anos. Na época, 
a Dilma devia ter uns 23 pra 24 anos. Talvez até menos. Enfim, daí quando nós fizemos isso, a primeira leva eu mandei cem desses manifestos pra se colher assinaturas. A Dilma, com muita habilidade, como era uma mulher visada, era casada com o (Carlos) Araújo e parece que ele era do Partidão, e ela podia ser presa política, podia assustar. O que ela fez? Ela procurou a Lícia Peres que era muito amiga dela, mulher de um vereador, presidente da Câmara, e em comum acordo procuraram a Mila Calduro, uma escritora, mulher da alta sociedade. Era engraçado, o marido era do Tribunal de Contas e o Movimento Feminino pela Anistia se deslocava num Mercedes do marido dela (risos). Quando eu cheguei no Rio Grande do Sul, eu falei: "Isso aqui é outro país. É outro mundo". A gente se deslocava em Mercedes. Eu fiquei no melhor hotel de lá, porque, sabe, se eu fosse ficar em qualquer hotelzinho furreca, eles iam incomodar. Como eu tava naquele hotelzão e tudo. Seguiam-nos o tempo todo. Uma hora lá que eles nos perderam de vista, a polícia nos perdeu de vista, foi quando nós fomos para a casa da Dilma. Mas sabe que aquele movimento chacoalhou o Rio Grande do Sul, porque o gaúcho é muito ativo e essa Lícia Peres é uma mulher muito inteligente. A Mila Calduro é uma mulher de valor. A Quita Brizola (Francisca Brizola Rotta) que era irmã do Brizola. Lá tínhamos umas 20 mulheres que valiam por uma pancada, porque no fundo nós precisávamos de mobilizadoras que retransmitissem... E eu fui para a televisão, falar. E sempre tive muita sorte. Quando a gente fala com o coração, não erra nunca. Não fica querendo falar com a cabeça, falar difícil não. E foi uma beleza. O Movimento Feminino pela Anistia foi a alavanca para as mulheres começarem a perceber que elas podiam e deviam. Porque o cidadão tem direitos e deveres. Nossos deveres nós devemos cumprir todos e direitos a gente tem que exigir. Não tem que pedir não, é exigir. Foi uma beleza. Depois de lá, vim pro Rio. Foi meio fracote num primeiro estágio, eu contava com a mulher do general Cunha Melo, que era uma mulher do maior critério, da maior decência, ela e também um general desses famosos que fizeram a resistência. Já eram senhoras de idade bem mais avançada do que a minha. Tinham princípios, sabiam $\circ$ que estavam fazendo, mas não sabiam mobilizar. E eu consegui, no Rio, quando a mãe de Jean Marc von der Veid (carioca, ex-militante da Ação Popular, ex-presidente da UNE e ex-preso político), que era casada com um suíço, me ofereceu um quarto ali na Rui Barbosa, um apartamento grande, imenso. Eu trabalhava muito de noite, porque quem tem filho pega esse hábito. Criança dá muito trabalho, a casa e tudo. E eu trabalhava muito de noite, porque eu mandava, o elo de ligação eram as cartas. E tudo feito à mão... [...]

\section{ARFD: E como se dava esse trabalho?}

TZ: Pra falar só da anistia em si, eu não conseguiria ter abertura. Teve o Ano Internacional da Mulher, cujas consignas eram: igualdade, desenvolvimento e paz. Meu marido era milico e ele sabia muito desse negócio da arte da guerra, estudava. Eu fazia Direito, gostava de arte e achava que tudo isso era um pouco de exagero. Mas quando eu me meti na política, eu vi o valor da estratégia, comecei a ler L'Art de la guerre. Tudo que não me interessava, que eu achava que era bobagem, eu comecei a me interessar. E a mulherada estava muito interessada. Você lembra de (19)60, a pílula. (19)64 foram quatro anos depois do negócio da pílula. Eu tenho muita pena dessa mocidade, frutos da geração da pílula, porque elas estavam ávidas para viver. Então como transar já não era aquele perigo, desembestou aquela liberdade, aquela pseudoliberdade, que a liberdade é uma coisa interior muito maior. Imagine se a liberdade do homem ou da mulher estivesse nos genitais. Coitados de nós, né? (risos). A liberdade está numa postura intelectual perante a vida, uma postura de princípios, de você escolher o que você quer pra você. Foi muito bonito, porque eu nunca mostrei a idade. Com 52 anos eu passava por 45. Não havia então muita defasagem entre eu e as moças. Sabe, era uma coisa engraçada porque gerava um encantamento, porque, geralmente, as mães delas coibiam, com medo da gravidez, e encontraram uma pessoa falando em liberdade, lutando pela anistia, com uma malinha nas mãos. Foi uma experiência muito boa pra mim, muito gratificante e, geralmente, também os homens não estavam acostumados. Principalmente no Nordeste, você sabe melhor que eu, o homem não estava acostumado a ver mulher sem coleira, mulher estava sempre com o marido ou com o filho. Sozinha era raro, mas por uma questão de necessidade, tudo custa dinheiro, avião, passagem, eu tinha de andar sozinha, eu e Deus. Até perguntavam: "A senhora não tem medo de andar sozinha?" Eu digo: "Não, eu não ando sozinha. Sou eu e Deus". O general dizia: "Mas Terezinha, você fala com Deus como se Deus fosse seu íntimo, amiguinho". Eu digo: "Nego, Deus é pai. A gente não conversa com o pai com amor, com confiança? Então, é isso aí". Se você começar a perceber, nada acontece por acaso. Nada. E eu nas minhas orações me punha como um instrumento do amor de Deus. Pombas, se eu estou como instrumento dele, ele tem que me dar (risos). E, olha, nunca me aconteceu absolutamente nada.

ARFD: A senhora era seguida?

TZ: Muito, muito. 
ARFD: Tinha telefone grampeado, essas coisas todas?

TZ: Tudo, tudo. Depois até aqui do Dops (Departamento de Ordem Política e Social), eu dei até muita risada. Eu acho que eles pensavam que eu era louca mesmo. Eu tinha um cachorro poodle que era uma beleza, chamava-se Zorba. E ele era horrível, vivia fugindo. Então arranjei uma mulher pra ele. Era a Flor. E, desse casamento, deu cinco cachorros. E então isso aqui era um canil, porque um não vai por isso, o outro não vai por aquilo. E eu saía muito com os cachorros por aí. Pois até fotografia minha com os cachorros tinha. É coisa de desocupado, né?

ARFD: E o fato do movimento ser feminino, eu gostaria que a senhora esclarecesse. Era vetada a presença de homens estatutariamente?

TZ: Era.

ARFD: Era uma estratégia de guerra?

TZ: Era uma estratégia de guerra.

\section{ARFD: Como foi esse processo?}

TZ: Os homens podiam vir, mas onde o homem vai, ele inibe. Você vai numa reunião de operários, de estudantes, tem lá um grupinho de mulheres. Se tem homens, eles inibem. Porque a mulher não foi treinada, ela não tem a velocidade mental porque sempre foi o homem que mandou. Ele sempre foi o chefe e patrão. Então as mulheres ficavam com medo de falar bobagem. Então foi arte da guerra mesmo. Era treino. E mulher com mulher se entende. E meu forte nunca foi mulher. Eu fui uma mulher muito bonita e meu forte nunca foi mulher, sempre foi homem (fala enfaticamente). E eu não sabia lidar bem com elas. Mas olha, Deus dá o frio conforme o cobertor. E a coisa foi muito bem. Tanto é que, quando nós começamos o Movimento, diziam - a turma do PC do B - porque tudo que tinha organizado eram eles que tinham feito. Ou então do PT também, que já estava nascendo. Eles queriam abocanhar. Eu dizia: "Não me venham fazer política dentro do Movimento, que nunca houve, viu?". Tanto é que você vê que, conquistada a anistia, que era o objetivo, acabou. Cada um foi fazer o que queria, porque isso era o certo.

\section{ARFD: Houve tentativas de aparelhamento?}

TZ: Houve tentativas. E eu dou nominalmente o nome: Luís Eduardo Greenhalgh (Membro fundador do PT, foi filiado de 1974 a 1980 ao MDB. Trabalhou como advogado de jornais alternativos. Foi liderança do Comitê Brasileiro pela Anistia). Ele era terrível. Mas eu me vinguei dele porque eu trabalhei pro Severino (Cavalcanti. Ex-deputado do Partido Progressista - PE, foi eleito presidente da Câmara dos Deputados em fevereiro de 2005. Representante do baixo clero, foi eleito prometendo elevar salários e melhorar as condições de atuação dos congressistas. Sete meses depois, renunciou por envolvimento em denúncias de corrupção). Foi a primeira tentativa de bote do PT foi pegar a presidência da Câmara. Eu tinha saído do hospital, nessa cadeira que você está vendo, eu liguei, eu trabalhei um dia, telefonando, pedindo voto pro Severino, porque a gente tinha que desmontar, porque se eles tivessem pego, a história era diferente. O nosso Movimento foi formado como uma sociedade civil e nós registramos no Cartório Medeiros. Lógico que eu também fazia isso pra minha defesa. Eu dizia: "Nós somos uma sociedade civil, organizada e piriri e pororó". Mas fazia parte da estratégia. Então, se reunia as mulheres que se conseguisse: 30, 50, 20. Tinha a presidente, a vice-presidente, a secretária, a tesoureira e uma que era tipo um coringa. Bom, e tinha as conselheiras. Tinha um bloco de 12 conselheiras. Esse pessoal do PC do B, principalmente da Bahia, quando queriam uma votação, que tudo era decidido por votação, não tinham compromisso com nada, não eram do Movimento. Eles entravam, eram passantes. Então era uma forma da gente se defender dos passantes, oportunistas. Você tinha de ter feito um estágio, pra ver se era aquilo mesmo que você queria.

\section{ARFD: Pra poder votar e participar das reuniões?}

TZ: Pois é. Porque, se não, você vê. Quando eles tinham alguma coisa que interessava a eles, levavam duas Kombis cheias de gente. Lógico que ganhava na votação. Ah, eu acabei com a brincadeira. Digo: "Não". Às vezes eu sou até chocante. Eu digo: "Escuta aqui, vocês estão pensando o quê? Aqui na Bahia nos cordões do carnaval vocês têm estatuto, têm que obedecer, só pode entrar com aquelas roupas deles que eles vendem, não podem dançar fora da corda. Se pro carnaval tem isso, no Movimento de Anistia não vai ter ordem?". Eu brincava: "Não é cu de mãe Joana, não!" (risos).

\section{ARFD: Como eles podiam participar?}

TZ: Eles jogavam esse tipo de gente e eu avisava: se livre dos oportunistas. Porque pra lutar com a fé e com o amor que nós lutamos tem que ter uma motivação. Uma pessoa que não tenha uma motivação nenhuma... Por exemplo, uma passante, essa precisa ficar sempre, porque inclusive 
pode ser plantada pela própria ditadura para arrebentar com o Movimento. Nós tivemos sempre muita sorte. E se os homens queriam estar lá para servir café, fazer uma compra enquanto a gente estava reunida, podia.

\section{ARFD: Eles só não podiam falar, nem votar, né?}

TZ: E nem votar e nem dar palpite. Eu dizia: "Muito bem, escreve e entrega, depois nós vamos discutir". Porque, senão, virava uma anarquia. O Movimento era feminino porque nós precisávamos treinar as mulheres a falar, elas terem confiança nelas mesmo, irem pra televisão. Você mesmo viu uma gravação hoje minha. Eu não nasci falando, não nasci velha, nem falando em televisão e nem organizando nada. A gente aprende. E aprender, minha filha, precisa a gente ter uma vontade muito grande e uma humildade muito maior.

ARFD:Havia uma preferência por mulheres que fossem familiares de presos políticos para integrarem o MFPA?

TZ: Não. Qualquer mulher podia. Geralmente quem vinha para nós eram os familiares de presos políticos, o que era até natural. E a gente acolhia e tudo. Mas tivemos muitas universitárias.

ARFD: Por ser um movimento só de mulheres, há relatos da utilização daquela figura tradicional da mãe. Como vocês usavam isso diante da ditadura?

TZ: Inclusive gorila (forma pela qual se referia aos militares golpistas) não foi filho de chocadeira. Mesmo os gorilas tinham mãe e havia um certo respeito. E quando a gente se investia do papel de familiar... Eu me investia do papel de mulher do general e eles se enquadravam, viu? Principalmente a mãe. Mãe todo mundo tem e, embora você discorde, nos presídios aqui é comum você ver a mãe do bandido lá: "Doutor, meu filho". Embora saibam que não é nada daquilo, a mãe é preservada. E lógico que, por uma questão de inteligência, a gente não ia pôr uma menina de sainha curta, mascando chicle pra ir lá falar com um gorila. Não tinha jeito (risos).

ARFD: Eram sempre as mais velhas, as mães?

TZ: Eram, as que tinham compostura. Porque era o próprio nome do Movimento que estava em jogo. Mas a gente se firmou na sociedade, viu? Daí a OAB (Ordem dos Advogados do Brasil) nos deu muito apoio, os professores universitários, os sindicatos, a Igreja. A Igreja foi nosso maior escudo.

ARFD: A senhora tem noção de quantos núcleos foram criados no Brasil?

TZ: Nós só não tivemos núcleo no Amazonas e nos territórios. No resto do país, em todos os lugares.

ARFD: Nas entrevistas que eu fiz com mulheres do MFPA no Ceará apareceram alguns conflitos. Algumas pessoas do Movimento acreditavam que o MFPA devia se envolver em questões mais amplas...

TZ: É porque tinha gente que queria fazer do Movimento Feminino pela Anistia uma alavanca. Queriam entrar, lógico, tinham meio caminho andado. E eu dizia, principalmente, eu trabalhei ombro a ombro com a lgreja, que foi um escudo, e com o Partidão, que o Partidão estava acostumado a trabalhar na sombra, escondido. E eu dizia: "Vocês não me venham com periquitagem (risos), não se faz política partidária". Conquistada a anistia, eu dissolvi o Movimento. Eu criei, eu, direção nacional. Quem quisesse continuar, continuava. Mas eu disse: "Quanto ao Movimento Feminino pela Anistia, nós somos residuais". Porque não tinha vindo a anistia ampla, sabe? Custou ainda pra vir e tudo. Somos residuais. Vamos transformar o Movimento em Movimento Feminino pelos Direitos Humanos.

ARFD: $E$ isso aconteceu?

TZ: Aconteceu. E até a Mila Calduro, que era uma mulher da maior lealdade e inteligência, me respondeu. Ela não queria desfazer porque também... Em Minas eu enfrentei um sério problema com a presidente de Minas, Helena Greco. Eles queriam fazer o que não era luta de anistia, e nessa hora você perde toda a sua força porque você já está avançando para um campo... Porque nós conquistamos respeitabilidade, realmente nós estávamos cumprindo a luta pela anistia.

ARFD: Vocês tinham medo de ser confundidas com os comunistas tão perseguidos naquele momento?

TZ: Não, não. O primeiro confronto que eu tive - você até vai dar risada - não foi nem com os gorilas. O primeiro confronto que eu tive foi com as feministas (se exalta) aqui de São Paulo.

ARFD: E por que, Dona Therezinha?

TZ: Ah, porque elas queriam se adonar do Movimento Feminino pela Anistia. Elas diziam que a luta do Movimento Feminino pela Anistia era feminista. Eu digo: "Não, vocês estão equivocadas. A luta 
do Movimento Feminino pela Anistia é uma luta de cidadania, da mulher cidadã. Não tem nada de feminista. Nós não estamos lutando por avanços. Depois cada um vai fazer o que quiser". Conquistada a anistia, cada uma vai fazer o que quiser. Pois tivemos um confronto, lá no sul.

\title{
ARFD: No Paraná?
}

TZ: Nós tivemos o jornal Brasil Mulher. Você chegou a ler? Foi no Paraná, sim. (Joana Borges) era jornalista, uma mulher extremamente inteligente, batalhadora, mas ela também se encantou com o Movimento Feminino pela Anistia e veio pra nós. Daí resolvemos fazer um jornal que era o Brasil Mulher. E o jornal era de homens e mulheres que viam na liberdade e piriri e pororó. E aquilo foi andando. Daí, as feministas que queriam uma vitrine... O Movimento Feminino pela Anistia foi uma vitrine, era uma novidade. E como ganhou respeito da opinião pública, elas queriam aderir. E daí começaram. E começou a tergiversar. Tanto é que eu me retirei. Eu me retirei do movimento (jornal), puxei o carro e elas ficaram falando sozinhas ao vento. Porque nós não éramos movimento de feministas, sabe? Era um movimento de cidadania.

\section{ARFD: Foi depois dessa saída que a senhora fundou o Maria Quitéria?}

TZ: É, foi daí que se tirou o Maria Quitéria.

\section{ARFD: A senhora estava contando sobre a escolha do nome. Também foi uma estratégia?}

TZ: Ah, também. Porque você veja, os milicos eram os nossos adversários, os que tomaram o poder num golpe de pirataria. Sabe, eles tomaram o poder. Foi golpe. Foi quartelada. Eles eram os nossos inimigos. Então, a gente tinha que bater no flanco deles como eles batiam no nosso. Até que nós não apanhamos muito não, porque a gente se fez respeitar. E mesmo porque eles também precisavam da anistia, porque todo movimento, todo golpe vai se desgastando, vai erodindo, vai surgindo gente nova com outras ideias e tudo. No final, eles estavam precisando tanto da anistia ou mais do que nós. Porque eles precisavam sair. Era uma ratoeira que eles precisavam sair ainda como os Estados Unidos vão sair lá do Irã, com rabo no meio das pernas. Tem que sair logo, como saíram do Vietnã. E foi uma coisa interessante. O que mais, filhinha?

\begin{abstract}
ARFD: Quando vocês começaram não existia nenhum movimento organizado que lutasse pela mesma causa. Vocês iniciaram..

TZ: Iniciamos isso. Daí, grande parte da esquerda cruzou para cima e dizia assim: a Zerbini é uma burguesona. Eu digo: "Por favor, completem: feliz e realizada". Eu luto por amor, não é por ódio. A luta pela anistia é luta pela cidadania. É uma luta que a gente quer que o país retome o leito e depois cada um vai fazer o que quiser, cada um vai seguir o seu caminho. Por dois anos nós trabalhamos nas sombras.
\end{abstract}

\section{ARFD: Como era esse trabalhar nas sombras?}

TZ: Eu gosto muito de história. Lá na Grécia, em Esparta, aquelas lutas... Nós não podemos tratar de fazer a luta à luz do dia. Trabalhar na sombra era trabalhar sem ser batendo panela, sem ser fazer o que eu fui fazer hoje que dei a cara, falei. Trabalhar nas sombras é fazer tudo em petit comité, fechado, que ninguém sabe. O povo gosta disso, o povo gosta de se engajar numa luta e que ela tenha uma direção.

\footnotetext{
ARFD: O surgimento do CBA (Comitê Brasileiro pela Anistia) foi uma consequência dos conflitos...

TZ: Isso. Porque daí, eles queriam tomar o movimento de mulheres. Houve um encontro nacional dos movimentos de anistia, eles punham uns nomes pomposos e nós não podíamos deixar aquilo solto. Então, a Lícia Peres era uma baiana bonita, ela foi, comprou chicle, comprou um Estadão, me deu o chicle e disse: eu sei que você não aguenta ficar quieta com provocação, masque esse chicle e leia esse jornal. Então, aí já tinha os encontros nacionais, já vieram os CBAs. E tinha um menino do Rio Grande do Norte que era o cão chupando manga, sabe (risos). Ele queria provocar. E a nossa vice-presidente, coitadinha, ela tinha uma dor de dente horrível. E ela precisou ir no dentista e arrancou um dente. Veio cheia de dor, disseram que tinha de pôr gelo. E eu e a Lícia fomos ajudar, claro. E ele não entendeu. Acho que pensou que a gente estava fazendo era descaso. Porque eles diziam: "Ficam andando de cá pra lá, ficam indo tomar cafezinho, indo tomar água, lendo jornal". Aquilo era pra mim, porque eu tava que tava (range os dentes). E a Lícia: "Olhe aqui. Não admito. Nosso movimento é um movimento democrático. Fique com seu estalinismo pra lá. Você chegou ontem, está acostumado com o estalinismo no Rio Grande do Norte. Vá fazer lá. Nós não. Nós somos democratas. Se não sabe, ela acabou de arrancar um dente" - a Margarida, coitada, tinha acabado de arrancar um dente - e eu mascando chicle pra não explodir (range os dentes). Mas eles vieram porque queriam tomar o movimento. Como eles
} 
não conseguiram, porque eu não dava chance... Eu dizia: "Não somos donas da anistia, nós não queremos ser". Em São Paulo, os universitários pegaram a bandeira da anistia. Eu chorei na rua quando eu falei do (Alberto) Goldman, que ele disse que eu ganhava as pessoas pela emoção. Quando eu vi os estudantes no fim do Viaduto do Chá (SP), com a bandeira da anistia, eu falei: "Graças a Deus". Quer dizer, nós não estávamos mais sozinhas. A Ordem (dos Advogados do Brasil) pegou a bandeira da anistia, um sindicato pegou a bandeira da anistia. Depois, juntar tudo aquilo era um apito. Não, eles queriam dirigir. Eles queriam tomar pra nos dirigir. Falei: não.

ARFD: A senhora acha que tinha um pouco de machismo nessa questão?

TZ: Tinha. Puro, puro machismo. Eles acham que porque nós não temos pênis, mulher não tem pênis, não pensa, não tem capacidade, não tem organização. Nos partidos políticos eu vejo isso. Eu sou dirigente partidária, eu vejo isso. A mulher, pra se sobressair, tem de ser ótima. Por isso que eu admiro essa menina, essa senadora Heloísa Helena. Ô menina porreta, porque olha, conseguiu com esse PSOL dela romper o cerco, porque é romper o cerco.

ARFD: Qual a imagem que a senhora acha que a ditadura tinha do MFPA? A senhora acha que vocês conseguiram enrolar bem a direita?

TZ: Não, a direita sabia bem quem nós éramos. E os militares também. Os militares, no fundo, eles admiravam, burros não eram, que eles sabem a arte da guerra, de todo esse jogo, das estratégias. E eles pensavam: "Quem sabe nós não vamos precisar delas?" Enquanto elas não avançarem demais, enquanto elas tiverem mansamente e docemente (risos). Tinha uma pessoa que era o Jarbas Passarinho, que eu fui visitá-lo porque ele era o líder da Arena. Nós fomos visitar o líder da Arena e do MDB. A chefe de gabinete do Jarbas Passarinho chamava-se Zoe. Quando nós chegamos eu me apresentei. Eu era uma mulher bonita e ele um homem muito bem educado e me perguntou: "Dona Terezinha, a senhora é mulher do médico ou do general?" Eu digo: "Não, eu tenho a honra de ser a mulher do general". Daí, ele ficou vermelho e disse: "A senhora vem aqui ao meu gabinete para me ofender?" Eu digo: "Eu não estou entendendo, senador. Se perguntassem para a sua mulher se ela era sua mulher, ela diria que tem a honra de ser sua mulher. Eu não estou entendendo onde o senhor quer chegar". Mas eu falei tão doce, falei com voz de uma menina de cinco anos. Ele caiu em si, sabe. E disse: "Me desculpe, me desculpe". Daí eu continuei falando no mesmo tom e tudo. Não, eu só quero honra porque eu tenho honra. E meu marido é um homem honrado. O senhor é militar, deve conhecer. O meu marido não é um baderneiro, como eu também não sou, como o senhor bem pode ver. Depois, quando a gente se encontrava naquele túnel do tempo, olha como é a história, ele fazia assim (acena de maneira tímida), com a mãozinha, me saudava escondido, me saudava, às vezes, com a cabeça. Sabe que a gente tinha medo que vissem a gente se cumprimentando? (risos). lam dizer que ele estava traindo e eu também. Quer dizer, porque nós tínhamos ideias diferentes, divergentes, nós não podíamos agir civilizadamente. Foi tão engraçado. Foi uma experiência de vida muito boa.

ARFD: A senhora era mulher de general, era advogada, mas não tinha essa vivência política. E de repente se vê como liderança nacional do Movimento Feminino pela Anistia. Como foi que o Movimento modificou sua vida, sua relação com o mundo, sua forma de encarar...

TZ: Ah, completamente diferente. Inclusive aqui em casa aconteceu uma coisa muito importante. O general tinha ciúmes, claro. Eu era uma mulher bonita, andando por esse mundo de Deus, sozinha. E ele encheu porque eu andava como caixeiro viajante, com malinha pra lá, pra cá. Telefonava gente de todo lado e tudo. Embora ele confiasse muito em mim, tem hora que enche, né? Ele disse: "Pois é - num desses dias de azedume que todos nós temos, de dormir descoberto (risos) - eu agora virei o marido da guerreira". Eu olhei bem nos olhos dele. Saiu a voz do meu coração: "Nego, por quantos anos eu fui a mulher do guerreiro? Isso nunca me diminuiu. A bandeira está no chão. Alguém tem que pegar. Você não entende?" (Diz com a voz embargada e emocionada). Ele abaixou a cabeça. Nunca mais, nunca mais...

\section{ARFD: Ele falou sobre isso.}

TZ: Nunca. Nunca mais. E aí eu vi como devia ser doloroso pra ele, porque eu saía e não sabia se voltava. Meus filhos eram pequenos, eu não era modelo. Você veja, veste a pele deles. Eles eram pequenininhos. Quando eles iam pra assistir a uma ópera, um balet, eles não iam como os filhos de deus comprar tíquete da bilheteria. Eles iam de carro, ficavam no camarote do governador, do prefeito. Era uma vida toda artificial, que não era uma vida de criança deles. De uma hora pra outra tudo isso voou. No colégio deles, a mãe baderneira. Criança não tem piedade, às vezes eles são impiedosos. Não é que toda criança é boazinha não. Mas aguentaram firmes, viu? Eu quase perco o meu filho que tem um ano e três meses de diferença da minha filha. Porque ele dizia: "Mamãe, eu não entendo. Você diz que gosta de mim, que eu sou seu amor, mas você em nome do amor do povo - olha, o amor do povo era uma coisa que não era concreta, ele era concreto, 
estava ali, podia deitar no meu colo, podia dormir comigo, pôr a cabecinha dele no meu peito fica andando pelo mundo". Quer dizer, foi doído, foi sofrido. E eu aprendi também a superar isso, viu. Eu digo: "Eu não posso me deixar vencer por chantagem". E cada um usa as armas que tem. Eles, coitadinhos, usavam a arma da chantagem. E eu que tinha lucidez tinha que dizer: "Eu amo vocês, o papai é o melhor pai do mundo". Porque o general se desdobrava. Meu irmão vivia aqui, minha mãe vinha dormir com eles todas as noites porque eles andavam brigando muito. Você sabe, eles sentiam a falta e brigavam. Olha, a minha vida mudou muito e eu passei a ver a vida com outros olhos. Porque eu nunca tinha sofrido. Essa cadeia que eu peguei foi a coisa melhor que aconteceu na minha vida.

\section{ARFD: A senhora passou seis meses?}

TZ: Praticamente um ano eu fiquei à disposição da ditadura. Na primeira fase três meses e depois três meses.

\section{ARFD: E por que exatamente a senhora fol presa?}

TZ: Porque eu ajudei na organização do Congresso de lbiúna. O Congresso de lbiúna foi o grande crime. E a verdade era uma só, depois que eu descobri, anos depois, que eles tinham cinco locais. Você veja que as coisas acontecem, não tem nada por acaso. Eu acho que eu era uma peça do destino, sei lá, que eu tinha de passar por isso. Porque, olha, nunca pensei... Depois, você sabe que eu gostei (risos). A política, quando é feita com princípios, ela é muito bonita.

\section{ARFD: O início dessa luta para a senhora então teve um caráter de honra quase que pessoal?}

TZ: Não, não só. A primeira motivação foi a indignação. Foi uma coisa pessoal de honra minha. Mas quando eu fui pra cadeia e vi o sofrimento do Bacuri (codinome do guerrilheiro Eduardo Collen Leite, torturado e executado pela ditadura), que eles torturaram, cortaram orelha, o sofrimento do (Frei) Tito, o sofrimento que a gente assistiu das famílias, o sofrimento da Maria Joana Teles, que foi uma operária, coitada. Desgraçaram a família dela. Tem gente boa. Tinha um delegado, eu já estava muito amargurada, e ele disse: "O que a senhora tem hoje que não sorri?". Porque eu tirava sarro deles, brincava. Tirava sarro mesmo, provocando. "Hoje a senhora está esquisita, o seu humor mudou. O que a senhora tem?" Eu digo: "Doutor, o senhor sabe, a minha companheira, a Maria, tem uma menina que se ela não entrar até hoje lá no Padre Chico ou na Sagrada Família até seis horas, ela perde a vaga dela". A menina era cega, a mãe presa aqui dentro. Ele disse: "Eu Ihe dou minha palavra de honra. A senhora não se preocupe com isso. Me diga onde ela está". Eu disse pra ele procurar a Maria porque eu não sabia. Ele disse: "Eu vou pegar e vou levar lá. A menina entra lá". E, realmente, cumpriu. Por incrível que pareça, não é que eu fosse agnóstica, mas como toda pessoa feliz, a gente lembra de Deus mais quando está no aperto. E no meio daquela infelicidade, eu vi que Deus existe. Existe porque na hora que eu mais precisava, a coisa acontecia. E uma coisa também que eu pude ver é que quando eu lutava, lutava. Porque eu tenho defeitos horríveis. Eu tenho uma fera dentro de mim que quando solta... Eu quero ser boa, eu luto por ser boa (risos), mas quando essa ferinha sai, minha filha... O general dizia: "Pelo amor de Deus, Terezinha, não tire os tamancos da bolsa". Porque eu sou neta de português. Mas sabe, me deu uma visão muito maior de Deus, da vida, da generosidade. E que nós estamos aqui puramente é de passagem. E a vida não é um banquete não, sabe. Você veio aqui para dar a sua pitada de sal. Uns dão mais, outros dão menos. Mas então, eu estou em paz, porque eu faço o que eu posso. Mesmo dentro da minha limitação hoje, eu faço o que posso.

\section{Referências}

ZERBINI, Therezinha Godoy. Anistia: semente da liberdade. São Paulo: Editora Salesianas, 1979.

Ana Rita Fonteles Duarte (iD) 0000-0002-2469-6044

Doutora em História Cultural pela Universidade Federal de Santa Catarina.

Professora Associada 1 do Departamento de História, ministra disciplinas nas áreas de Teoria da História e Prática de Ensino na graduação. Integra as linhas Cultura e Poder e Memória e Temporalidades no Programa de Pós-Graduação em História da UFC. Mestra em História Social e graduada em Comunicação Social/Jornalismo também pela UFC. Tem experiência nas áreas de História e gênero, história das mulheres, gênero e ditadura no Brasil. Coordena o Grupo de Pesquisas e Estudos em História e Gênero (GEPEHG), na UFC.

Universidade Federal do Ceará, Centro de Humanidades, Departamento de História

Avenida da Universidade, 2762, Benfica

60020-180 - Fortaleza - CE - Brasil

(85) 3366 - 7738/3366- 7739 - secretaria.historia@ufc.br 
anaritafonteles@uol.com.br

COMO CITAR ESSE ARTIGO DE ACORDO COM AS NORMAS DA REVISTA

DUARTE, Ana Rita Fonteles. "O Movimento Feminino pela Anistia na luta contra a ditadura no Brasil: entrevista com Therezinha Zerbini”. Revista Estudos Feministas, Florianópolis, v. 27, n. 1, e53564, 2019.

\section{CONTRIBUIÇÃO DE AUTORIA}

Não se aplica.

\section{FINANCIAMENTO}

Não se aplica.

\section{CONSENTIMENTO DE USO DE IMAGEM}

Não se aplica

APROVAÇÃO DE COMITÊ DE ÉTICA EM PESQUISA

Não se aplica

\section{CONFLITO DE INTERESSES}

Não se aplica

\section{LICENÇA DE USO}

Este artigo está licenciado sob a Licença Creative Commons CC-BY. Com essa licença você pode compartilhar, adaptar, criar para qualquer fim, desde que atribua a autoria da obra.

\section{HISTÓRICO}

Recebido em 23/10/2017

Aprovado em 07/1 1/2018 